\title{
Use of a geographic information system to map cases of measles in real-time during an outbreak in Dublin, Ireland, 2011
}

G Fitzpatrick (gabriel.fitzpatrick@hse.ie) ${ }^{1}$, M Ward ${ }^{1}, 0$ Ennis ${ }^{1}$, H Johnson², S Cotter 3 , M J Carr ${ }^{4}$, B 0’Riordan ${ }^{4}$, A Waters ${ }^{4}$, J Hassan ${ }^{4}$,

J Connell ${ }^{4}$, W Hall ${ }^{4}$, A Clarke $^{1}$, H Murphy ${ }^{1}$, M Fitzgerald ${ }^{1}$

1. Department of Public Health, Health Service Executive (HSE) East, Dr Steeven's Hospital, Dublin, Ireland

2. Health Intelligence Ireland (HII), Dr Steeven's Hospital, Dublin, Ireland

3. Health Protection Surveillance Centre (HPSC), Dublin, Ireland

4. National Virus Reference Laboratory, University College Dublin, Belfield, Dublin, Ireland

In 2011, there was a large measles outbreak in Dublin. Nationally 285 cases were notified to the end of December 2011, and 250 (88\%) were located in the Dublin region. After the first case was notified in week 6 , numbers gradually increased, with 25 notified in June and a peak of 53 cases in August. Following public health intervention including a measles-mumpsrubella (MMR) vaccination campaign, no cases were reported in the Dublin region in December 2011. Most cases (82\%) were children aged between 6 months and 14 years, and 46 cases (18\%) were under 12 months-old. This is the first outbreak in Dublin to utilise a geographic information system for plotting measles cases on a digital map in real time. This approach, in combination with the analysis of case notifications, assisted the department of public health in demonstrating the extent of the outbreak. The digital mapping documented the evolution of two distinct clusters of 87 (35\%) cases. These measles cases were infected with genotype D4-Manchester recently associated with large outbreaks across Europe. The two clusters occurred in socio-economically disadvantaged areas and were attributable to inadequate measles vaccination coverage due in part to the interruption of a school-based MMR2 vaccination programme.

\section{Introduction}

Measles is a highly infectious disease that can result in serious morbidity and mortality. It has been a notifiable disease in Ireland since January 1988. An effective and safe vaccine against measles is available, and two doses of a measles-containing vaccine are recommended for individual protection. In addition, 95\% uptake of each dose across the general population is required to prevent outbreaks. Measles vaccination was introduced to Ireland in 1985 , initially as a monovalent vaccine and since 1988 as a component of the measles-mumps-rubella (MMR) vaccine. The national vaccination policy from 2008 recommends children receive the first dose of $M M R$ vaccine (MMR1) at the age of 12 months from their family doctor. The second dose of MMR vaccine (MMR2) is given at the age of 4-5 years generally through the school-based vaccination programme [1].

Although the number of measles cases in Ireland has decreased substantially since the introduction of the MMR vaccine [2], there have still been a number of significant measles outbreaks in Ireland [3]. In 2010, a total of 426 measles cases were notified nationally. These cases clustered among certain population groups, including members of the Irish Traveller and Roma communities and children whose parents object to vaccination on philosophical or religious grounds [4].

The World Health Organization (WHO) recognises eight clades $(\mathrm{A}-\mathrm{H})$ of measles viruses which comprise 23 established genotypes [5]. The WHO Measles and Rubella Laboratory Network (LabNet) requires virological surveillance of wild-type measles viruses and genetic characterisation of a $450 \mathrm{nt}$ fragment of the nucleoprotein gene to monitor virus transmission, discriminate between imported and endemic cases, and document interruption of transmission $[6,7]$. Molecular epidemiological analysis of wild-type measles viruses in Ireland over the previous decade have shown exclusively clade D viruses to be circulating. Genotype D8 strains present in 2002/03 were supplanted by genotype D7 in 2003, and from 2004 to 2012, numerous distinct clusters of genotype D4 predominated [8]. The D4-Enfield strain (MVs/Enfield.GBR/14.07[D4]), documented first in Irish Travellers in the United Kingdom (UK), was identified in Irish cases in 2007/08 in a school outbreak in Dublin associated with travel to Germany [8]. A variant of D4-Enfield, termed D4-Hamburg, was described in the Irish Traveller and Roma communities in Ireland in the latter part of 2009 and early 2010 (e.g. MVs/Kerry.IRL/40.09[D4]) with subsequent spread to other citizens who refused vaccination $[4,9]$. This 
genotype was also linked to cases in Northern Ireland (MVs/Belfast.GBR/50.09[D4]) [10].

The Dublin region is divided into eight Community Care Areas (CCA1- CCA8). Each CCA is an administrative division of the health service with responsibility for immunisation activities in their area. In Ireland, data on the MMR1 uptake rate at 24 months of age are available at the national and regional level on a quarterly basis [11]. The national and Dublin region uptake rate was $77 \%$ in 1999 (the first year data became routinely available for national reporting), however, marked improvements in MMR1 uptake have occurred since then. For the third quarter of 2011 , the national uptake rate was $93 \%$ and the Dublin region uptake rate was $91 \%$. Although these figures represent an improvement in vaccination coverage, they are still below the WHO recommended target of $95 \%$ required to provide herd immunity.

The measles outbreak that occurred in Dublin in 2011 involved 250 cases. The majority ( $82 \%$ ) were children aged between 6 months and 14 years. The aim of this study was to digitally plot cases of measles as they occurred in real time during the outbreak using a geographic information system (GIS) that also mapped the varying levels of socio-economic deprivation across Dublin. This facilitated the identification of clusters of measles in areas of deprivation and assisted the direction of Public Health interventions.

\section{Methods}

The measles data used in this report were extracted from the Computerised Infectious Disease Reporting system (CIDR) on 14 March 2012. Crude incidence rates of measles cases were calculated nationally and for CCA1-CCA8 using population data from the 2011 Census [12].

When a case of measles was notified, the home address details from the CIDR were cross-referenced with the GIS within the application Health Atlas Ireland (HAI). This provided XY co-ordinates for each notified case, and these co-ordinates were then digitally mapped. Throughout this measles outbreak, a continuously updated map of the Dublin region was available showing the exact location of all cases. The outbreak map was also colour-coded to show the socio-economic deprivation level by electoral division using the Haase and Pratschke index [13].

$\mathrm{HAl}$ is a web application portal supporting health service planning and monitoring in Ireland. The system integrates open-source GIS, database and statistical components. The GIS arm integrates the national post office GeoDirectory that allows address location and address cleansing functionality nationally.

Notified measles cases were assigned case classifications using the Case Definitions for Notifiable Diseases [14]. The measles case definition is composed of clinical, laboratory and epidemiological criteria:
Clinical: any person with fever and maculopapular rash and at least one of the following: cough, coryza or conjunctivitis;

Laboratory: At least one of the following: Isolation of measles virus from a clinical specimen, detection of measles virus nucleic acid in a clinical specimen, measles virus-specific antibody response characteristic for acute infection in serum or oral fluid, or detection of measles virus antigen by direct fluorescent antibody test in a clinical specimen using measles-specific monoclonal antibodies;

Epidemiological: any person with an epidemiological link by human-to-human transmission.

Cases were classified as follows:

Possible case: any person meeting the clinical criteria; Probable case: any person meeting the clinical criteria and with an epidemiological link;

Confirmed case: any person not recently vaccinated and meeting the clinical and the laboratory criteria.

Measles virus genotyping was performed according to WHO guidelines by bidirectional sequencing of the 3' hypervariable region of the nucleoprotein gene (NP-HVR) on an ABI3500 genetic analyzer [15]. Genbank accession numbers JQ866618, JQ866619 and JX315600 were assigned for the measles genotypes described in this study following submission to the Measles Nucleotide Surveillance (MeaNS) database (http:// www.who-measles.org), a joint project between the Health Protection Agency (London, UK) and the WHO.

A maximum likelihood phylogenetic tree of measles genotype D4 sequences from the outbreak was built based on partial (456 bp) nucleoprotein gene sequences. The tree includes reference measles genotype D4 sequences obtained from GenBank and measles virus sequences detected in Ireland since 2004. The phylogenetic tree was built using PAUP*) version 4.0 Beta 10 [16] and annotated in FigTree version 1.3.1 (http://tree.bio.ed.ac.uk/software/figtree/).

\section{Outbreak description}

In 2011, the first case of measles was notified in week 6 in a 22 month-old child from North Dublin (CCA-8) who did not attend daycare facilities. This case was laboratory-confirmed. From weeks 6 to 15, an average of one to two cases per week were notified, however, no epidemiological links between these cases could be identified. These 13 cases were widely distributed across the Dublin region with no obvious geographical clustering (Figure 1).

During week 16, two outbreaks were identified. The first occurred in a tertiary educational institution in North Dublin, where two students developed clinical measles. One was laboratory-confirmed and the other was epidemiologically linked to the confirmed case. No international travel was associated with these cases. Neither case had received any MMR vaccinations. The 
Measles cases in Dublin, Ireland, weeks 1-16, 2011 ( $\mathrm{n}=18)$

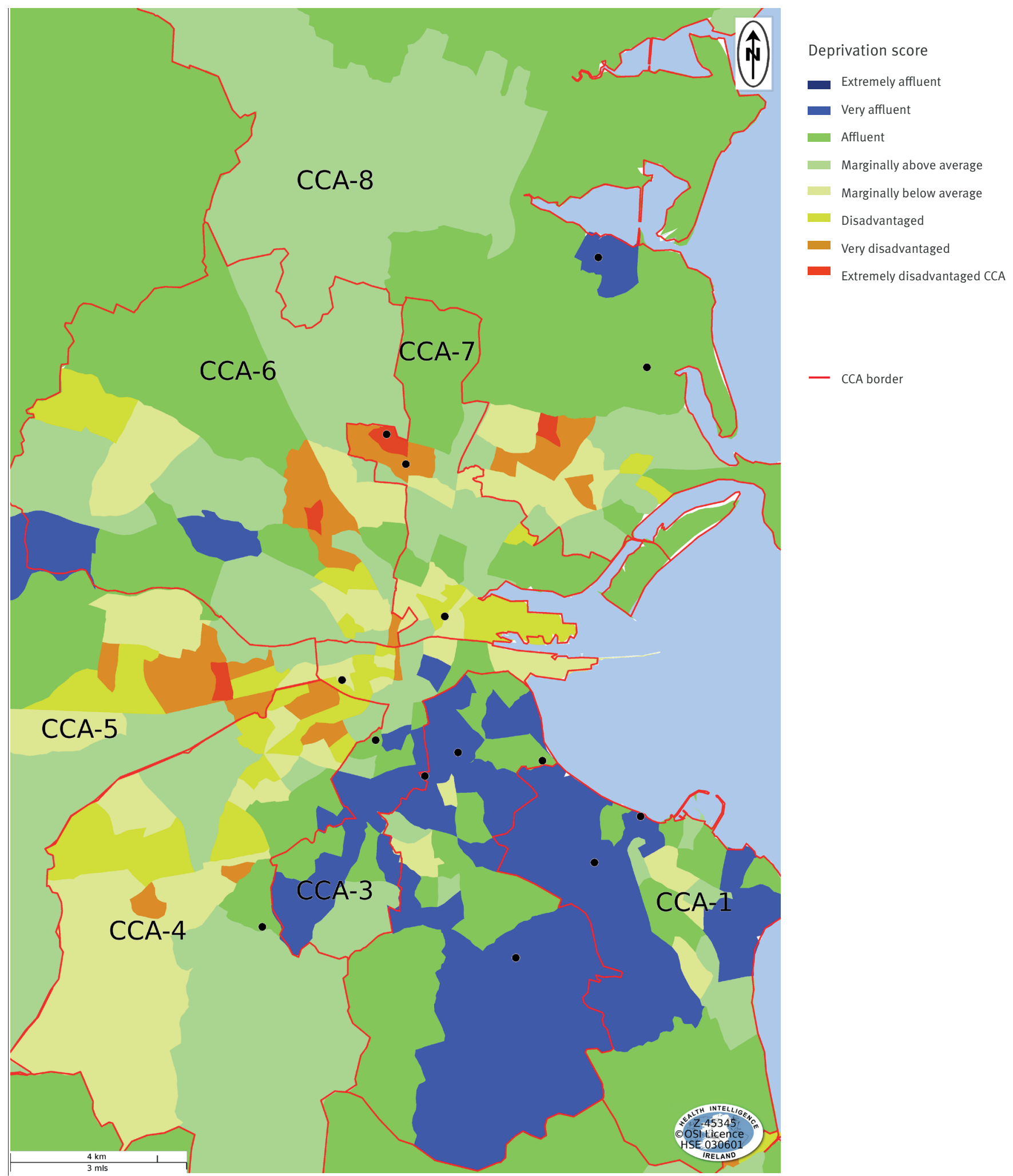

The black spots indicate areas in Dublin where cases occurred. The map is colour-coded to show the different levels of socio-economic deprivation across Dublin. 


\section{FIGURE 2}

Measles cases in Dublin, Ireland, weeks 1- 36, 2011 ( $\mathrm{n}=161)$

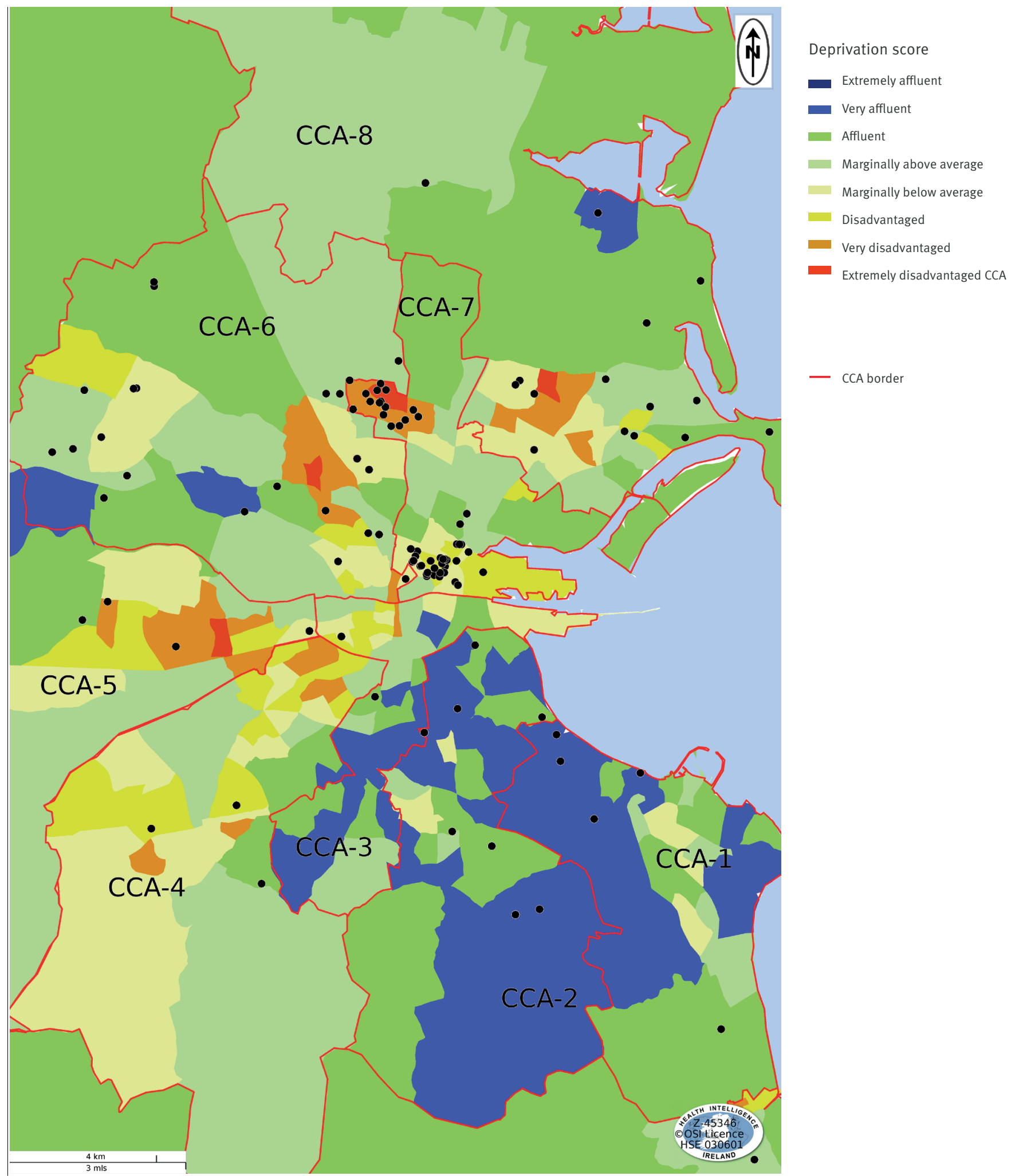

The black spots indicate areas in Dublin where cases occurred. The map is colour-coded to show the different levels of socio-economic deprivation across Dublin. 
Measles cases in Dublin, Ireland, weeks 1-52, $2011(\mathrm{n}=250)$

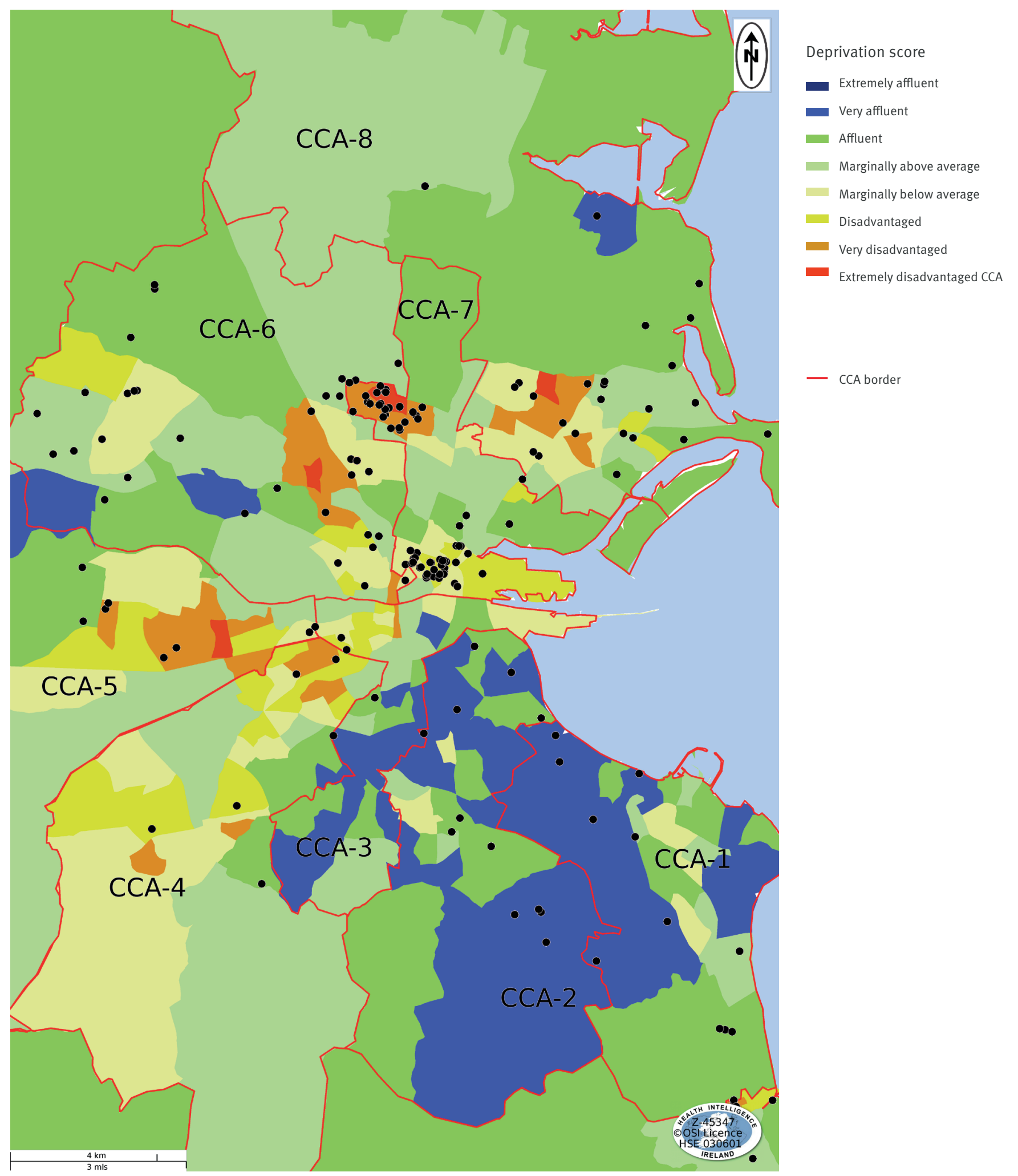

The black spots indicate areas in Dublin where cases occurred. The map is colour-coded to show the different levels of socio-economic deprivation across Dublin. 


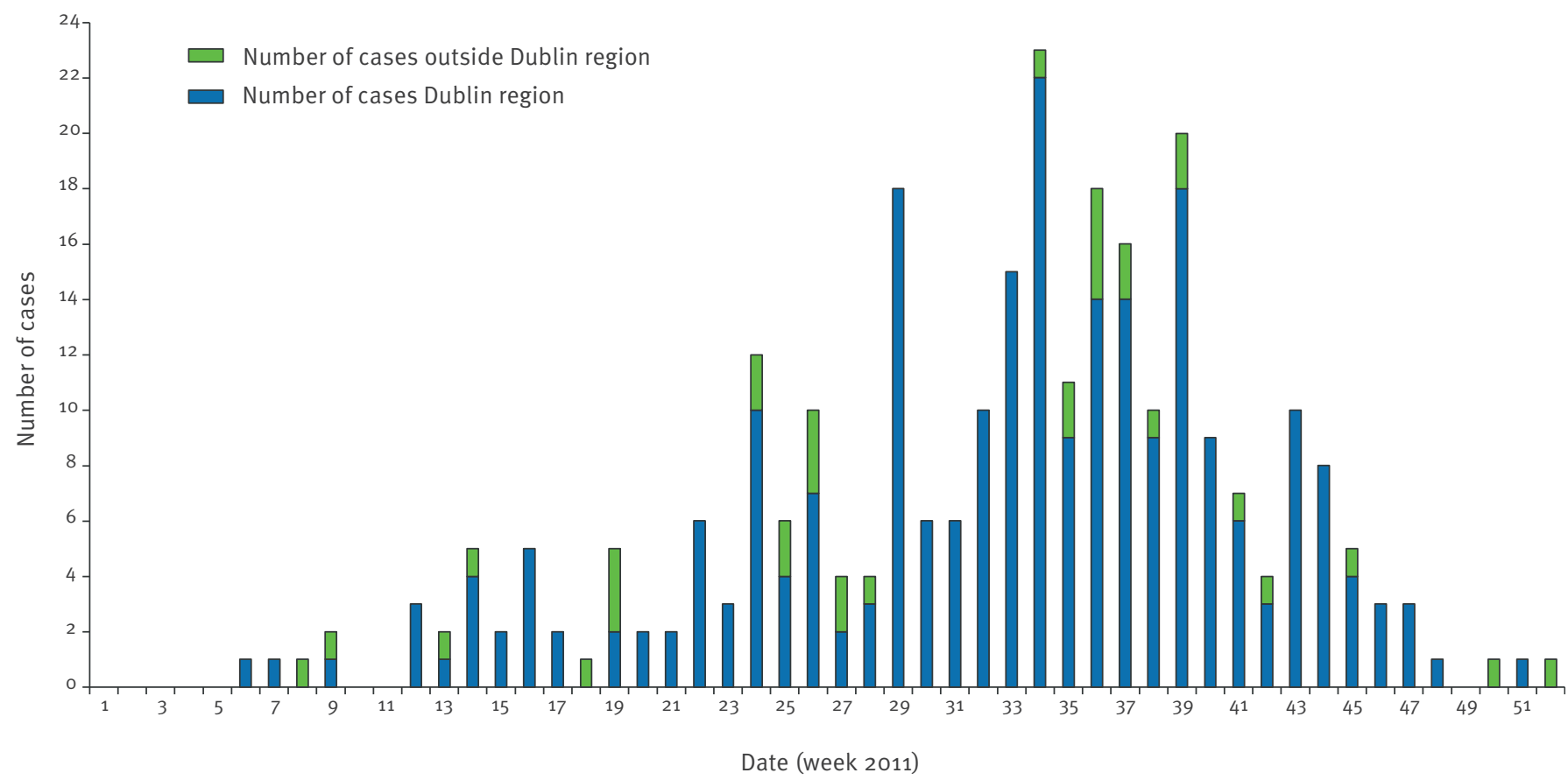

second outbreak in week 16 occurred in a primary school in South Dublin (CCA-2) with three children confirmed to have measles. None of these children had received $M M R$ vaccinations.

Between weeks 17 and 36, an additional 16 outbreaks in Dublin were notified. Seven of these outbreaks were found in Community Care Area-7 (CCA-7) which is the most densely populated CCA in Dublin with 3,632 persons per $\mathrm{km}^{2}$. The largest outbreak in 2011 began during week 35 in a residential summer camp for disadvantaged children in the inner city. The summer camp is located in North County Dublin and provides one week of daytime activities and overnight accommodation for children. A total of 25 confirmed cases of measles were notified and epidemiologically linked to this camp. Overall by week 36 , the initial clustering of cases in two distinct and socially disadvantaged areas of CCA-7 was evident on digital mapping (Figure 2).

From week 37 to 52, public health medical staff investigated five measles outbreaks in Dublin. Two of these outbreaks occurred in family homes, two in childcare facilities and one in a hospital. The number of measles notifications dropped dramatically from week 45 onwards. Further clustering of cases in two geographically distinct regions of CCA-7 occurred during weeks 37 to 52 (Figure 3).

By the end of week 52, 285 cases were notified nationally, of which 250 (88\%) were located in the Dublin region (Figure 4 ). By week 52 , the national crude incidence rate (CIR) for measles cases was 5.9/100,000. In the Dublin region, the CIR for 2011 was 15.0/100,000, however, in CCA-7 it was 63.9/100,000. Of the 250 cases ( $54 \%$ male) notified in the Dublin region, 127 ( $51 \%)$ were laboratory-confirmed, 58 (23\%) were probable cases and 65 (26\%) were possible cases.

Measles virus genetic analysis was performed on 23 cases from Dublin in 2011 by sequencing the NP-HVR, and phylogenetic analysis confirmed 22 were genotype D4 (Figure 5). A single genotype D8 case was also detected in week 35 without history of travel, suggesting this genotype was also circulating in Ireland. That strain, MVs/Dublin.IRL/35.11/2[D8], was $100 \%$ identical over the 456 bp typing region to genotype D8 cluster 1 viruses described in India since 2007 (MVi/Villupuram. IND/07.07) and more recently in the UK (MVs/Chester. GBR/3.09) and Italy (MVs/Padova.ITA/07.11/1). Two distinct lineages of measles genotype D4 were found to be circulating in Dublin in 2011 between weeks 18 to 41 , one represented in Figure 5 by MVi/Dublin. IRL/18.11 ( $n=9), 100 \%$ identical to D4-Manchester (MVs/ Manchester.GBR/10.09), and the other exemplified by MVs/Dublin.IRL/26.11 $(n=13)$, identified between weeks 26 to 41,2011 . The latter measles virus was found to be associated with the outbreak in CCA-7 and corresponds to a distinct variant of $\mathrm{D}_{4}$ with a single synonymous mutation compared to MVs/Manchester.GBR/10.09 (Figure 5).

At present there is no published data on MMR2 uptake at 5 years of age in Ireland. Each CCA in the Dublin region has an immunisation department that files MMR2 returns. In 2011, CCA-7 reported an MMR2 uptake at 5 years of $75 \%$. The remaining CCAs in the Dublin region reported an MMR2 uptake at 5 years of 
Phylogenetic analysis of measles genotype D4 outbreaks, Dublin, Ireland, $2011(\mathrm{n}=22)$

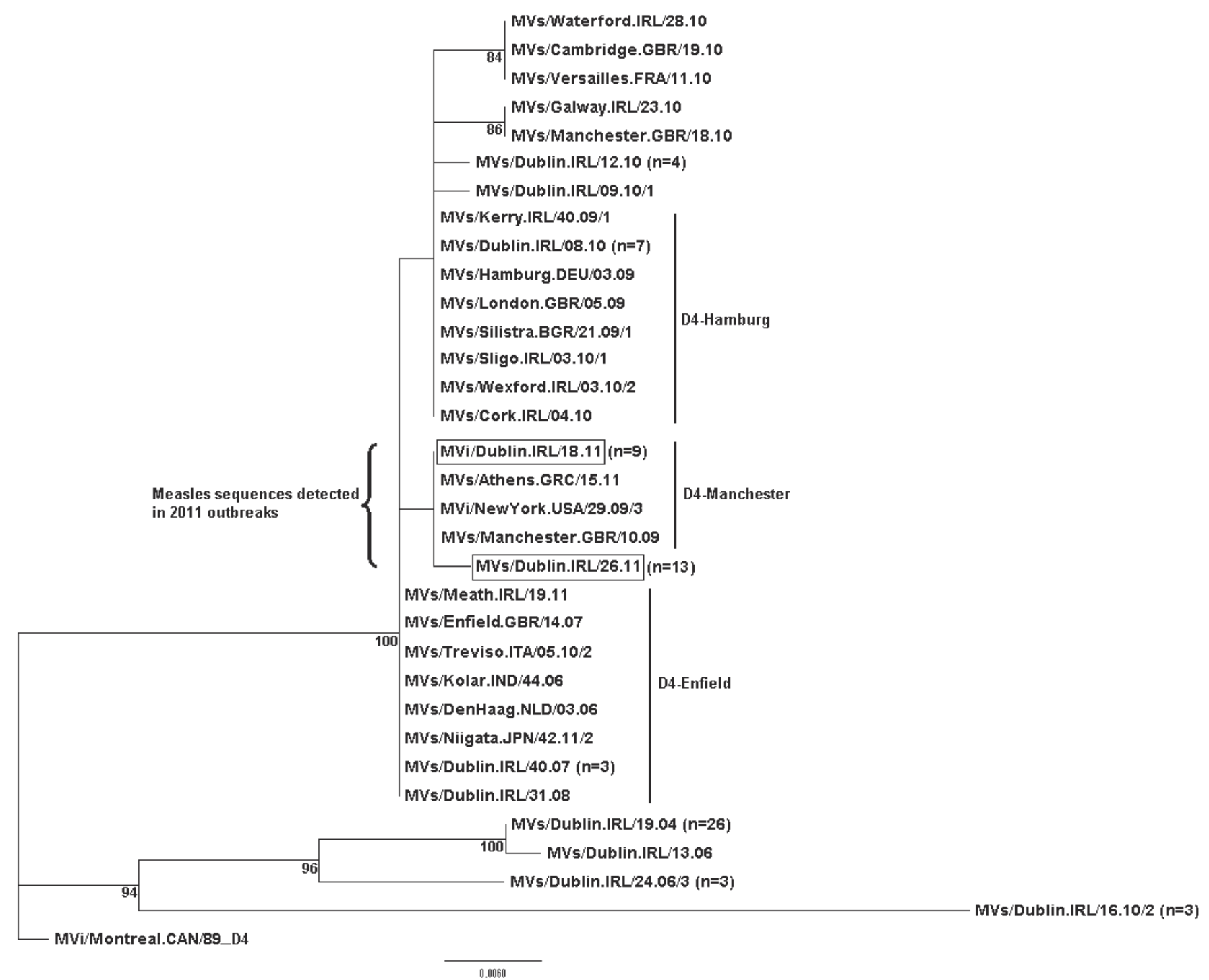

The measles virus NP-HVR sequences associated with the outbreaks in Dublin are highlighted.

greater than $90 \%$ in 2011 . These data were not independently verified. All age groups were affected during the current outbreak (Figure 6). The majority of cases $(82 \%)$ were in children aged between 6 months and 14 years, with $46(18 \%)$ cases occurring in those under 12 months of age.

Of the 250 notified cases, 145 (58\%) had received no MMR vaccination and for $38(15 \%)$ cases vaccination status was documented as either "unknown" or "not specified". Fifty-seven (23\%) cases were reported to have had one dose of MMR vaccine, while 10 (4\%) cases reported to have received two doses (documented evidence available only for two of them). Twenty-four measles cases (10\%) were hospitalised in the Dublin region and no deaths were recorded. The reasons for admission included seizures $(n=1)$, pneumonia $(n=2)$, pyrexia $(n=1)$, dehydration due to nausea and vomiting $(n=1)$, tonsillitis $(n=1)$, and the remaining were not specified $(n=18)$. In CCA-7, 10 cases were admitted to hospital ( $42 \%$ of all hospitalised cases).

The GIS component of $\mathrm{HAl}$ achieved an initial $78 \% \mathrm{XY}$ co-ordinate match for the 250 measles case addresses supplied to it by the CIDR. The remaining $22 \%$ of addresses had to be matched by manual review of the data entered in the address field of the CIDR. Of those initially unmatchable addresses, $85 \%(n=47)$ contained substantial spelling mistakes and the remaining $15 \%$ $(n=8)$ did not contain the minimum information for the software to match the address to the reference geodirectory. 


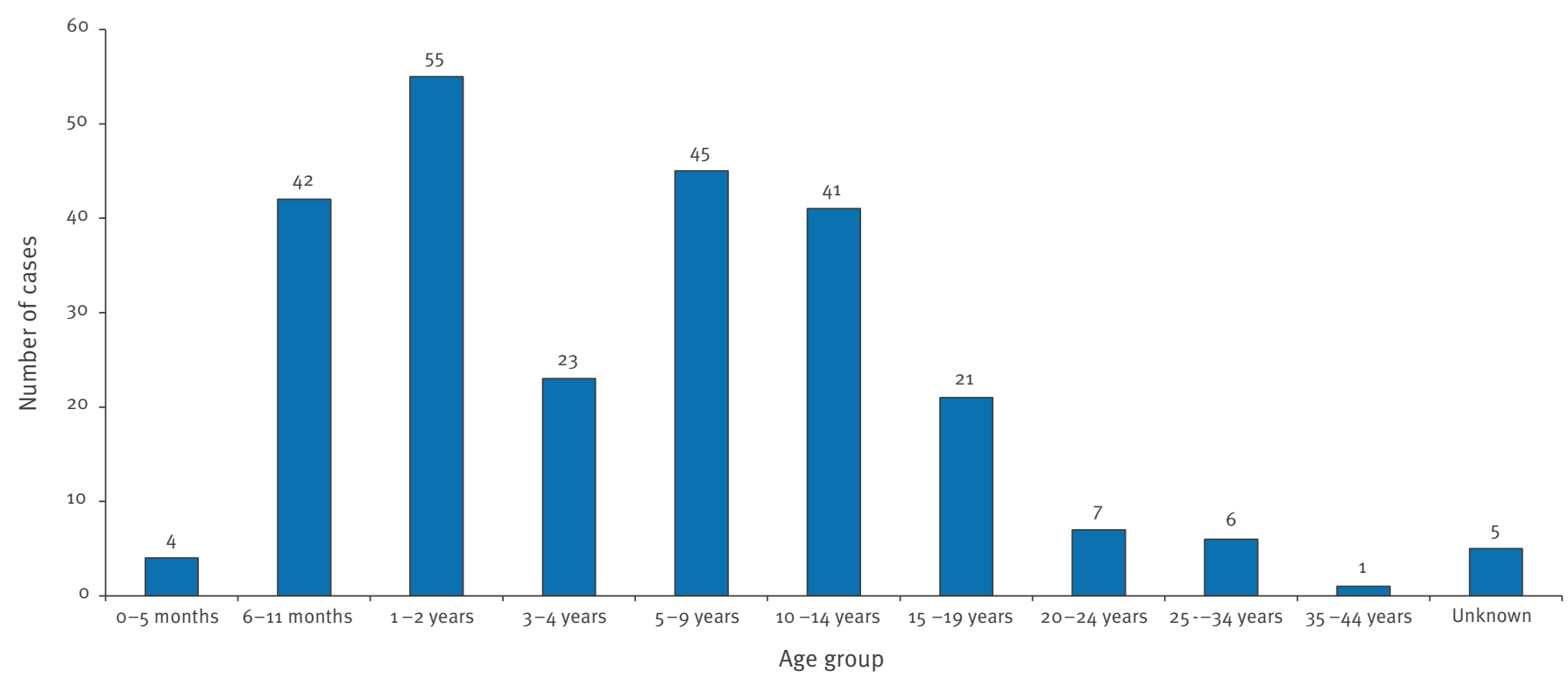

\section{Control measures}

An outbreak control team was convened with medical, nursing and administrative representatives from public health, community medicine, HPSC and the National Immunisation Office (NIO). The outbreak control measures undertaken included:

\section{General guidance}

Information on control measures to contain the measles outbreak was distributed to all relevant institutions such as hospitals and general practice surgeries. This guidance stated that all children should receive MMR vaccination at 12 months and 4-5 years of age. If a child had not received two MMR vaccines by five years of age, it was recommended that they should be vaccinated opportunistically as soon as possible. All relevant guidance was posted on the websites of the NIO and the HPSC [17].

\section{Contact tracing}

Public health medical staff followed up measles cases as a priority by advising on appropriate immunisation, arranging swabs and liaising with schools, childcare facilities and parents.

\section{Media campaign}

Radio and print media were utilised to inform the public of the measles outbreak and the importance of having children vaccinated with MMR.

\section{Healthcare staff}

Healthcare professionals were reminded of the importance of infection control measures to prevent measles transmission within clinics and hospitals by rapidly isolating cases when they presented.

\section{North Inner City intervention (including CCA-7)}

Due to the number and age profile of measles cases it was recommended that children aged 6-11 months in CCA-7 receive MMR vaccine during the outbreak period if they had contact with a probable or confirmed case of measles within the previous 72 hours. These children were then advised to complete their measles vaccination schedule in accordance with the current Irish national guidelines. It was also recommended that MMR2 be expedited for children older than one year who had already received MMR1 if they had been in contact with a probable or confirmed case of measles in the previous 72 hours.

From 7 to 16 September 2011, emergency vaccination teams attended primary schools, focussing on those located in CCA-7. The vaccination teams consisted of medical, nursing and administrative staff from the Community Medical Service and the Department of Public Health. Twenty-eight of 51 schools in the affected area were prioritised for vaccination, and MMR vaccine was offered to those children who were not up to date with their vaccination schedule. A total of 1,772 MMR vaccine doses were administered.

\section{Discussion}

The measles outbreak in 2011 demonstrates that Ireland has to make substantial progress to meet the WHO goal of eliminating measles in Europe by 2015 [18]. The outbreak in Dublin highlighted that measles cases clustered in two distinct areas of CCA-7 in North Inner City Dublin. The likely reason for this was MMR vaccination uptake rates below 95\%. In CCA-7, MMR1 and MMR2 are given to children in the surgery of the 
family doctor, whereas in all other CCAs in the Dublin region, MMR2 is offered to children by vaccination teams that attend schools and provide the vaccine on site with parental consent. CCA-7 discontinued providing a school-based MMR2 vaccination programme in 2000 primarily due to resource issues. Each September, the local immunisation office for $\mathrm{CCA}-7$ receives the name, age and address of every child commencing primary school education in CCA-7. This local immunisation office then sends a letter to the parents of these children indicating they should bring their child to the family doctor to receive the MMR2 vaccine free of cost. As MMR2 uptake rates are lower for CCA-7 than surrounding CCAs, this suggests that a school-based MMR2 vaccination programme is more successful at improving MMR2 uptake levels and therefore should be reinstituted in CCA-7 to minimise the transmission of measles to susceptible children and adolescents $[19,20]$.

The national quarterly MMR1 uptake rates at 24 months [4] indicate that since 1999, all national quarterly reports have recorded MMR1 uptake rates of below $95 \%$ at 24 months. This suggests that Ireland has built up a large reservoir of unvaccinated individuals capable of sustaining future outbreaks of measles. Similar situations have been anticipated and occurred in larger European countries such as Germany, Italy and France, where MMR vaccine coverage has remained below $95 \%$ for a substantial number of years [21].

The two large geographical clusters in the city developed in areas designated disadvantaged and extremely disadvantaged [13] in CCA-7. CCA-7 had an MMR2 uptake rate of $75 \%$ for 2011 , as reported by the local immunisation office, even though MMR vaccination was available at no cost from the local family doctor. An important question facing public health and local government in CCA-7 is how to convince parents to bring their unvaccinated children to the family doctor in a deprived area awaiting the re-introduction of schoolbased MMR2 vaccination teams. One programme currently available is the voluntary Community Mothers Programme [22]. This involves experienced mothers visiting and offering support to first-time mothers in deprived areas of Dublin. The programme has achieved substantial improvements in vaccination uptake rates for those children whose mothers are enrolled in the programme [22-24]. An important component of this programme is that visiting experienced mothers are from the same area as the first-time mother. However, in order for the Community Mothers Programme to have a meaningful effect on vaccination uptake rates in CCA-7 it would have to be extended to cover a greater number of families over a more prolonged period of time. The location of measles outbreaks in areas of deprivation is also an issue for other European countries [25] and shows that vaccination education and delivery designed for the general population is unlikely to be successful in deprived inner city areas. Tailored evidence-based interventions, such as the Community
Mothers Programme, in these locations are required [26]. The combination of low vaccination rates, deprivation, high population density and a lack of specific preventative measures for disadvantaged areas together led to the two clusters in CCA-7.

The finding that $18 \%$ of cases were younger than 12 months indicates that the issue of low vaccination uptake has had a disproportionate effect on the infant population in Dublin. This change in the age profile of measles infections in Ireland may in part be explained by the reduced incidence of natural measles infection in women of child-bearing age and therefore a decrease in the level of maternal protective anti-measles IgG. It is unlikely that a mother who has received MMR will transfer adequate protective antibody to prevent measles infection in children under 12 months of age. As a result infants younger than 12 months may be increasingly dependent on further improvements in vaccine coverage, which needs to reach $95 \%$ to afford the necessary herd immunity.

Since 2007, six different measles virus genotypes ( $B_{3}$, $\mathrm{D}_{4}, \mathrm{D}_{5}, \mathrm{D} 8, \mathrm{D} 9, \mathrm{H}$ ) have been described in Europe [27]. The 2011 outbreak in Dublin comprised two distinct genotype D4 strains, one of which was $100 \%$ identical over the typing region to D4-Manchester which is widely circulating in Europe [28] and to a newly described D4 variant with a single synonymous nucleotide substitution compared to MVs/Manchester.GBR/10.09. Measles virus genotype $\mathrm{D}_{4}$ represents the predominant autochthonous strain identified in recent outbreaks in Dublin and the rest of Ireland before 2012 and also in Austria, Belgium, Bulgaria, France, Germany, Greece, Italy, the Netherlands, Romania, Spain and the United Kingdom $[8,9,29]$. We have identified a single measles genotype D8, cluster 1 virus circulating contemporaneously with the genotype D4 viruses during the outbreak in 2011. Genotype D8 is endemic in Bangladesh, Nepal and India [30] and has also been described in outbreaks in Italy and France [31,32]. Measles genotype $\mathrm{G}_{3}$ is endemic in southeast Asia, and transmission of this genotype appeared to have been interrupted with the last cases described in 2006, however, since late 2010 cases of $G_{3}$ were described in the UK, Spain, France, Germany, Switzerland and also in a Canadian national with a recent history of travel to Europe [3335]. The results of the genotyping data in this study suggest a limited number of clade D viruses (genotype D4 and D8) are presently circulating in Ireland with no evidence for circulation of the novel $G_{3}$ described elsewhere in Europe. This is characteristic of endemic transmission of measles virus and contrasts with geographic regions approaching measles elimination, where an endemic virus is absent and the co-circulation of multiple imported genotypes is generally seen [36]. The molecular characterisation of circulating measles viruses is of increasing importance in confirming the absence of endemic infection in Ireland as Europe aims for the elimination of measles by 2015 . 
The use of the geographical information system for the real-time digital mapping of cases identified an issue with the recording of addresses on the computerised infectious disease reporting system. Health Atlas Ireland's geodirectory contains an exhaustive list of addresses within Ireland obtained from the national postal directory. The finding that $22 \%$ of addresses from the CIDR were not recorded accurately suggests improvements with regard to inputting the data should be sought. Accurate address information is extremely important for mapping large numbers of cases within short periods of time. This highlights that any georeferencing system is only as good as the quality of the data that it receives. The GIS utilised during this outbreak identified geographic clusters at the elementary level through the plotting of disease occurrences at residential addresses of patients. Our system did not account for varying background population density. An area of high population density will have a greater number of cases than an area of lower population density even when the crude incidence rates for both areas are the same. It is preferable that when GIS is employed during an outbreak that the system incorporates kernel functionality [37] to filter the noise caused by spatially varying population density in order to identify spatial clusters [38]. However, a separate calculation using census data [12] confirmed that the CIR for CCA-7 was greater than that of the surrounding regions. Another limitation of the GIS technique in infectious disease epidemiology and outbreak investigation is that mapping of diseases will describe the 'where' but not the 'why there' of the outbreak [39]. Nevertheless map patterns can provide potential clues as to what is causing the disease which can then be followed up by further investigation [40]. Modern GIS software that incorporates multiple map layers with advanced geostatistical analysis is expensive. This cost is further increased by the necessity of having to employ personnel or train existing personnel on how to use the complex software. Public health departments under financial constraints must carefully weigh the advantages and disadvantages of GIS before allocating budgets.

The use and level of complexity of geographical information systems being used internationally varies greatly and is dependent on the resources available. In Canada, a GIS has been developed that can simulate the spread of a communicable disease, such as measles, within a populated area. The system is built on a complex algorithm that describes both the communicable disease stages and the life paths of people responsible for the transmission of disease within an urban area [41]. This system is composed of multiple layers including information on population density, the transportation network and different types of land use. Turkey relatively recently used a GIS to retrospectively assess a measles outbreak in Istanbul. The process involved geo-referencing the addresses of measles cases and attaching various epidemiological information such as vaccination status by using symbols [42]. When GIS is utilised in developing countries it must have minimal costs attached. The Ministry of Health in Nicaragua in conjunction with Columbia University in New York have combined Google Earth imaging with a GIS subsidised through the Global Fund to produce a low-cost innovative method to track infectious diseases in resource-poor settings [43]. This consequently allows public health to focus attention on areas where cases cluster.

International literature has confirmed that compulsory vaccination at school entry achieves higher uptake rates when compared to other methods $[44,45]$. Therefore a more prudent approach to prevent measles outbreaks occurring in Dublin would be to introduce compulsory MMR vaccination for those wishing to attend school education. Ireland's situation reflects the larger epidemic of measles occurring on the continent of Europe at present [46] and this particular outbreak has demonstrated how novel technologies such as GIS can assist with the management of outbreaks. However, as public health budgets diminish, this measles outbreak has also shown that the resources to provide school-based MMR vaccination programmes should be protected and expanded in order to help prevent future outbreaks of measles in Ireland.

\section{Acknowledgments}

We would like to thank our colleagues from the Department of Public Health - East, the Health Protection Surveillance Centre, the National Virus Reference Laboratory and the National Immunisation Office for their support in preparing this article.

\section{References}

1. Corcoran B. Driving change in immunisation. The role of the national immunisation office 2005-2011. Health Service Executive: National Immunisation Office, 2012. Available from : http://www.immunisation.ie/en/EXTRADOWNLOADS/ PDFFile_17039_en.pdf

2. Health Protection Surveillance Centre (HPSC). Annual reports on measles in Ireland. Dublin: HPSC. Available from: http:// www.hpsc.ie/hpsc/A-Z/VaccinePreventable/Measles/ Publications/AnnualReportsonMeaslesinlreland/

3. McBrien J, Murphy J, Gill D, Cronin M, O’Donovan C, Cafferkey MT. Measles outbreak in Dublin, 2000. Pediatr Infect Dis J. 2003;22(7):580-4. Epub 2003/07/18.

4. Gee S, Cotter S, O'Flanagan D, on behalf of the national incident management team. Spotlight on measles 2010: Measles outbreak in Ireland 2009-2010. Euro Surveill. 2010;15(9):pii=19500. Available from: http://www. eurosurveillance.org/ViewArticle.aspx?Articleld=19500

5. Rota PA, Brown K, Mankertz A, Santibanez S, Shulga S, Muller CP, et al. Global distribution of measles genotypes and measles molecular epidemiology. J Infect Dis. 2011;204 Suppl $1: S_{514-23}$ 
6. Rota PA, Brown KE, Hubschen JM, Muller CP, Icenogle J, Chen $\mathrm{MH}$, et al. Improving global virologic surveillance for measles and rubella. J Infect Dis. 2011;204 Suppl 1:S506-13.

7. Rota PA, Featherstone DA, Bellini WJ. Molecular epidemiology of measles virus. Curr Top Microbiol Immunol. 2009;330:129-50.

8. Carr MJ, Conway A, Waters A, Moran J, Hassan J, Hall WW, et al. Molecular epidemiology of circulating measles virus in Ireland 2002-2007. J Med Virol. 2009;81(1):125-9.

9. Mankertz A, Mihneva Z, Gold H, Baumgarte S, Baillot A, Helble $R$, et al. Spread of measles virus D4-Hamburg, Europe, 20082011. Emerging infectious diseases. 2011;17(8):1396-401. Epub 2011/08/02

10. Smithson R, Irvine N, Hutton C, Doherty L, Watt A. Spotlight on measles 2010: Ongoing measles outbreak in Northern Ireland following an imported case, September-October 2010. Euro Surveill. 2010;15(43): pii=19698. Available from: http://www. eurosurveillance.org/ViewArticle.aspx?Articleld =19698

11. Health Protection Surveillance Centre (HPSC). Immunisation uptake statistics quarterly reports. Dublin: HPSC. Available from: http://www.hpsc.ie/hpsc/A-Z/VaccinePreventable/ Vaccination/ImmunisationUptakeStatistics/QuarterlyReports/

12. Central Statistics Office (CSO). This is Ireland - Highlights from census 2011. Dublin: CSO; 2012. Report No. Available from: http://www.cso.ie/en/media/csoie/census/documents/ census2011pdr/Census $\% 202011 \% 2$ oHighlights $\% 20$ Part $\% 20$ $1 \% 20$ web\%2072dpi.pdf

13. Haase T, Pratschke J. The new measures of deprivation in the Republic of Ireland. Dublin: Pobal; 2008; Available from: http://trutzhaase.eu/publications/ the-new-measures-of-deprivation-in-the-republic-of-ireland/

14. 14. Health Protection Surveillance Centre (HPSC). Case definitions for notifiable diseases. Dublin: HPSC; Mar 2012. Available from: http://www.hpsc.ie/hpsc/NotifiableDiseases/ CaseDefinitions/

15. World Health Organization. Global measles and rubella laboratory network--update. Wkly Epidemiol Rec. 2005;80(44):384-8

16. Swofford DL. PAUP*: phylogenetic analysis using parsimony (*and other methods). Version 4.0. Sunderland, Massachusetts: Sinauer Associates; 2003.

17. Health Protection Surveillance Centre (HPSC). Measles guidance. Dublin: HPSC. Available from: http://www.hpsc.ie/ hpsc/A-Z/VaccinePreventable/Measles/Guidance/

18. Regional Committee for Europe. Renewed commitment to elimination of measles and rubella and prevention of congenital rubella syndrome by 2015 and sustained support for polio-free status in the Copenhagen: World Health Organisation regional Office for Europe; Sep 2010. Available from: http://www.euro.who.int/_data/assets/pdf file/0008/119546/RC60_edoc15.pdf

19. Lindley MC, Boyer-Chu L, Fishbein DB, Kolasa M, Middleman $A B$, Wilson $T$, et al. The role of schools in strengthening delivery of new adolescent vaccinations. Pediatrics. 2008;121 Suppl 1:S46-54.

20. Joyce-Cooney J, Meagher G, Quinn C, Cavanagh I. Achieving $95 \%$ uptake in an immunisation programme--not an impossibility. Ir Med J. 2003;96(9):268-70.

21. Lévy-Bruhl D, Pebody RG, Veldhuijzen I, Valenciano M, Osborne K. ESEN: a comparison of vaccination programmes - Part three: measles mumps and rubella. Euro Surveill. 1998;3(12):pii=112. Available from: http://www.eurosurveillance.org/ViewArticle. aspx?Articleld=112

22. Molloy B. Community mothers programme. Annual report 2010. Dublin: Health Service Executive; 2010; Available from: http://www.lenus.ie/hse/bitstream/10147/136802/1/ CommMothers2010.pdf

23. Johnson Z, Howell F, Molloy B. Community mothers' programme: randomised controlled trial of non-professional intervention in parenting. BMJ. 1993;306(6890):1449-52.

24. Thornton L, Barry J, Kelly A. A policy paper on public health care issues for low income families with children. Dublin: Combat Poverty Agency; Nov 2000. Available from: http:// lenus.ie/hse/bitstream/10147/46616/1/2372.pdf

25. Wright JA, Polack C. Understanding variation in measlesmumps-rubella immunization coverage--a population-based study. Eur J Public Health. 2006;16(2):137-42.

26. Baker D, Garrow A, Shiels C. Inequalities in immunisation and breast feeding in an ethnically diverse urban area: crosssectional study in Manchester, UK. J Epidemiol Community Health. 2011;65(4):346-52.

27. Mankertz A, Mulders MN, Shulga S, Kremer JR, Brown KE, Santibanez S, et al. Molecular genotyping and epidemiology of measles virus transmission in the World Health Organization
European Region, 2007-2009. J Infect Dis. 2011;204 Suppl 1:S335-42.

28. Pfaff G, Lohr D, Santibanez S, Mankertz A, van Treeck U, Schönberger K, et al. Spotlight on measles 2010: Measles outbreak among travellers returning from a mass gathering, Germany, September to October 2010. Euro Surveill. 2010;15(50):pii=19750. Available: http://www.eurosurveillance. org/ViewArticle.aspx?Articleld=19750

29. European Centre for Disease Prevention and Control (ECDC). European monthly measles monitoring (EMMO). Stockholm: ECDC; Jun 2011; Available from: http://ecdc.europa.eu/en/ publications/Publications/2011_June_measles_montly.pdf

30. Duraisamy R, Rota PA, Palani G, Elango V, Sambasivam M, Lowe L, et al. Molecular characterization of wild-type measles viruses in Tamil Nadu, India, during 2005-2006: relationship of genotype D8 strains from Tamil Nadu to global strains. J Med Virol. 2012;84(2):348-57. Epub 2011/12/16.

31. Filia A, Tavilla A, Bella A, Magurano F, Ansaldi F, Chironna M, et al. Measles in Italy, July 2009 to September 2010. Euro Surveill. 2011;16(29):pii=19925. Available from: http://www. eurosurveillance.org/ViewArticle.aspx?Articleld=19925.

32. Waku-Kouomou D, Freymuth F, du Chatelet IP, Wild TF, Horvat $B$. Co-circulation of multiple measles virus genotypes during an epidemic in France in 2008. J Med Virol. 2010;82(6):1033-43.

33. Brown KE, Mulders MN, Freymuth F, Santibanez S, Mosquera MM, Cordey S, et al. Appearance of a novel measles $\mathrm{G}_{3}$ strain in multiple European countries within a two month period, 2010. Euro Surveill. 2011;16(17):pii=19852. Available from: http://www.eurosurveillance.org/ViewArticle. aspx?Articleld $=19852$

34. Cilla G, Montes M, Artieda J, Piñeiro L, Arriola L, PérezTrallero $\mathrm{E}$. Measles genotypes $\mathrm{D}_{4}$ and $\mathrm{G}_{3}$ reintroduced by multiple foci after 15 years without measles virus circulation, Gipuzkoa, the Basque Country, Spain, March to June 2011. Euro Surveill. 2011;16(43):pii=19997. Available from: http://www. eurosurveillance.org/ViewArticle.aspx?Articleld=19997.

35. López Hernández B, Laguna Sorinas J, Marín Rodríguez I, Gallardo García V, Pérez Morilla E, Mayoral Cortés JM. Spotlight on measles 2010: An ongoing outbreak of measles in an unvaccinated population in Granada, Spain, October to November 2010. Euro Surveill. 2010;15(50):pii=19746. Available from: http://www.eurosurveillance.org/ViewArticle. aspx?Articleld=19746.

36. Rota PA, Rota JS, Redd SB, Papania MJ, Bellini WJ. Genetic analysis of measles viruses isolated in the united states between 1989 and 2001: absence of an endemic genotype since 1994. J Infect Dis. 2004;189 Suppl 1:S160-4.

37. Bailey T, Gatrell A. Interactive spatial data analysis. London: Longman; 1995.

38. Goovaerts P, Jacquez GM. Accounting for regional background and population size in the detection of spatial clusters and outliers using geostatistical filtering and spatial neutral models: the case of lung cancer in Long Island, New York. Int J Health Geogr. 2004;3(1):14.

39. Howe G. National Atlas of Disease Mortality in the United Kingdom. London: Nelson; 1963.

40. McKee Jr KT, Shields TM, Jenkins PR, Zenilman JM, Glass GE. Application of a geographic information system to the tracking and control of an outbreak of shigellosis. Clin Infect Dis. 2000;31(3):728-33.

41. Perez L, Dragicevic S. An agent-based approach for modeling dynamics of contagious disease spread. Int J Health Geogr. 2009;8:50.

42. Ulugtekin N, Alkoy S, Seker DZ. Use of a geographic information system in an epidemiological study of measles in Istanbul. J Int Med Res. 2007;35(1):150-4.

43. Chang AY, Parrales ME, Jimenez J, Sobieszczyk ME, Hammer SM, Copenhaver DJ, et al. Combining Google Earth and GIS mapping technologies in a dengue surveillance system for developing countries. Int J Health Geogr. 2009;8:49.

44. Fogarty KJ, Massoudi MS, Gallo W, Averhoff FM, Yusuf H, Fishbein D. Vaccine coverage levels after implementation of a middle school vaccination requirement, Florida, 1997-2000. Public Health Rep. 2004;119(2):163-9.

45. Centers for Disease Control and Prevention (CDC). Effectiveness of a middle school vaccination law--California, 1999-2001. MMWR Morb Mortal Wkly Rep. 2001;50(31):660-3.

46. Steffens I, Martin R, Lopalco PL. Spotlight on measles 2010: Measles elimination in Europe - a new commitment to meet the goal by 2015. Euro Surveill. 2010;15(50):pii=19749. Available from: http://www.eurosurveillance.org/ViewArticle. aspx?Articleld $=19749$ 